\title{
Guangdong Province Industrial Structure on Regional Economic Growth and the Impact of Economic Fluctuations
}

\author{
Feng Yang ${ }^{1}$, Jialin Liu ${ }^{1} \&$ Haiying Ma ${ }^{1}$ \\ ${ }^{1}$ School of Economics, Northwest University for Nationalities, Lanzhou, China \\ Correspondence: Haiying Ma, Associate professor, School of Economics, Northwest University for Nationalities, \\ Lanzhou 730124, China. E-mail: lxmahaiying8888@163.com
}

Received: July 5, 2015

doi:10.5430/ijfr.v6n3p180
Accepted: July 17, 2015

Online Published: July 20, 2015

URL: http://dx.doi.org/10.5430/ijfr.v6n3p180

\begin{abstract}
Guangdong Province is one of the China's rapid economic developments, but in the post-crisis era, has some risks emerging in Guangdong Province, forced economic restructuring and optimizing and upgrading the industrial structure must be to speed up the process. Through rationalization of industrial structure and industrial structure, the sensitivity coefficient and the influence coefficient for measurement and analysis, identify leading industries to obtain concrete suggestions.
\end{abstract}

Keywords: industrial structure, economic growth, economic fluctuations

\section{Introduction}

The study of the industrial structure in Guangdong Province in China before 2010 foreign-investment-led research on the main body, evolved into the post-crisis era of regional space and comprehensive study of the economic and financial aspects of the trend. Qiumuling (2010) research, optimization and upgrading of industrial structure in Guangdong province must enhance regional financial support, sound policy of the financial system. Zhouyuan (2011), Guangdong Province, large space gap, seriously inhibiting the optimization and upgrading of industrial structure, must coordinate urban and rural development, with emphasis on rural development of the financial sector. To study, from a single factor affecting multiple factor study on development trends, industry structure, but few research articles of economic fluctuations. According to the data of the theil index about industry structure, this paper firstly analyzes that the industry structure has an influence on economic growth and fluctuation basiced on the general method of moments (GMM). Then, by calcutating the input-output table, we can obtain the strategic industies that the influence coefficient and sensitivity coefficient are both more than 1. Finally we conclude that excessive development of tertiary industry causes the great economic fluctuation. The policy about advancing strategic industies resonably, especially the tertiary industry is presented. The government should encourage the enterprise of secondary industry expanding production chain and deep processing.

\section{Models, Methods and Data}

\subsection{Models and Methods}

Using 1970-2014 industrial structure rationalization and advanced industrial structure as basic data obtained though modeling the impact on the economic.

$$
\mathrm{y}_{i t}=\gamma_{i}+\beta_{1} \ln T L_{i t}+\beta_{2} \ln T S_{i t}+u_{i t}
$$

$\mathrm{T}$ means time, y means economic growth or economic fluctuations, lnTL means after the logarithm of the rationalization of industrial structure $\operatorname{lnTS}$ means after the logarithm of the optimization of industrial structure. In order to measure the interactions between them, further the formulas below:

$$
\mathrm{y}_{i t}=\gamma_{i}+\beta_{1} \ln T L_{i t}+\beta_{2} \ln T S_{i t}+\beta_{3}\left(\mathrm{y}_{i t} * \ln T L_{i t}\right)+\beta_{4}\left(y_{i t} * \ln T S\right)+u_{i t}
$$

In order to eliminate the influence of the individual in the province, got difference schemes through the difference: 


$$
\Delta \mathrm{y}_{i t}=\beta_{1} \Delta \ln T L_{i t}+\beta_{2} \Delta \ln T S_{i t}+\beta_{3}\left(\Delta \mathrm{y}_{i t} * \Delta \ln T L_{i t}\right)+\beta_{4}\left(\Delta y_{i t} * \Delta \ln T S\right)+\Delta u_{i t}
$$

Industrial structure is obtained after the impact on economic growth and fluctuations in the economy, in order to further clarify the policy implications, according to leading industry influence on the larger economic role, through 2007, Guangdong provincial input-output tables, are based on input-output tables get sensitivity coefficient and coefficient is greater than 1 the leading industry sectors, further analysis and policy recommendations. The following is the calculation process of induction coefficient and the influence coefficient of industry:

$$
\sum_{j=1}^{n} X_{i j}+Y_{i}=X_{i}(i=1,2, \ldots, n)
$$

Input-output equations is, according to the substitution of direct input coefficient (5)

$$
a_{i j}=\frac{x_{i j}}{x_{j}}(i, j=1,2, \ldots \ldots, n)
$$

The direct input coefficient and forms:

$$
\begin{gathered}
\sum_{j=1}^{n} a_{i j} X_{j}+Y_{i}=X_{i}(i=1,2, \ldots, n) \\
X_{i}-\sum_{j=1}^{n} a_{i j} X_{j}=Y_{i}(i=1,2, \ldots,,,,, n)
\end{gathered}
$$

As the form of the matrix:

$$
(I-A) X=Y
$$

The inverse:

$$
(I-A)^{-1}=\left[\begin{array}{lllc}
A_{11} & A_{12} & \cdots & A_{1 n} \\
A_{21} & A_{22} & \cdots & A_{2 n} \\
\vdots & \vdots & & \vdots \\
A_{n 1} & A_{n 2} & \cdots & A_{n n}
\end{array}\right]
$$

The calculation of the coefficient sensitivity and the coefficient influence:

$$
\begin{gathered}
S_{i}=\frac{\frac{1}{n} \sum_{j=1}^{n} A_{i j}}{\frac{1}{n^{2}} \sum_{i=1}^{n} \sum_{j=1}^{n} A_{i j}}(i, j=1,2 \cdots, n) \\
T_{j}=\frac{\frac{1}{n} \sum_{i=1}^{n} A i j}{\frac{1}{n^{2}} \sum_{i=1}^{n} \sum_{j=1}^{n} A_{i j}}
\end{gathered}
$$

\subsection{The Variables and Data}

This data is from the perspective of dynamic; the two main aspects of the change of the economy industry are high industrial structure and industrial structure. In the rationalization of the industrial structure, the Theil index by Wang shaoping (2007) year study indicates that it is a reasonable indicator to measure the industrial structure, the formula as follows:

$$
T L=\sum_{i=1}^{n}\left(\frac{Y_{i}}{Y}\right) \ln \left(\frac{Y_{i}}{L_{i}} / \frac{Y}{L}\right)
$$

According to $\mathrm{Wu}$ Jinglian (2008) study, the economic structure of services is an important symbol of industrial structure upgrading. The ratio of tertiary industry tertiary output and the second industry value as the indicator of advanced industrial structure.

Based on the study of economic fluctuations, using the HP filter analysis, economic output is divided into trend potential output and the periodic components that output gaps, the following is the formula: 


$$
\sum_{\mathrm{t}=1}^{\mathrm{T}}\left(\ln \mathrm{Y}_{\mathrm{t}}-\ln \mathrm{Y}_{\mathrm{t}}^{*}\right)+\lambda \sum_{\mathrm{t}=2}^{\mathrm{T}}\left[\left(\ln \mathrm{Y}_{\mathrm{t}+1}^{*}-\ln \mathrm{Y}_{\mathrm{t}}^{*}\right)-\left(\ln \mathrm{Y}_{\mathrm{t}}^{*}-\ln \mathrm{Y}_{\mathrm{t}-1}{ }^{*}\right)\right]^{2}
$$

But this decomposition and not to break the trend and cyclical, so according to Aghion et al. (2006) suggested that the economic observation period is divided into several stages.Put the each stage of the economic growth of standard deviation as a measure of economic fluctuations. Meanwhile China studies suggest average economic growth phase to eliminate the effect of mean. This text uses the above method. Following is the formula to measure economic fluctuations:

$$
\operatorname{vol}_{i t, t+T}=\operatorname{std}\left(\ln T_{i t+T}-\ln Y_{i t}\right) / \frac{1}{T} \sum_{k=t}^{t+T} g_{i k}
$$

Because each stage of rationalization of industrial structure and advanced industrial structure is unstable relationships, in order to further clarify the analysis, inspect the effects of industrial structure on economic growth.

\section{Empirical Analysis}

Through the 1970-2014 output value of Guangdong province and the three industry workforce calculated TL and TS, as shown below.

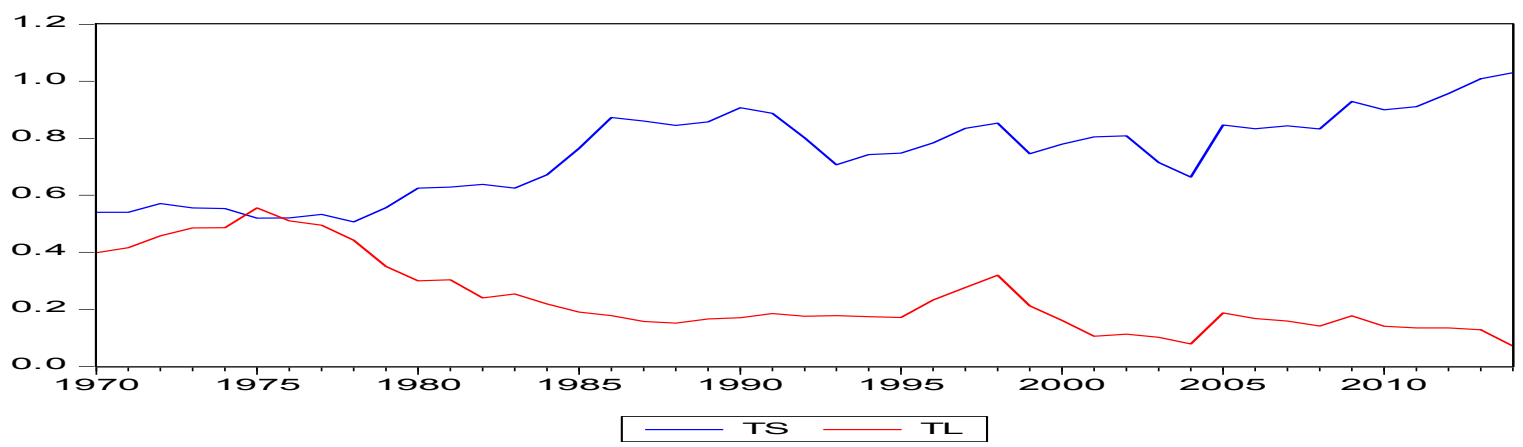

By figure can see, TL and TS of Guangdong Province in 1970-1977 change big, 1970-1977 the reform ago. TL and TS slowly rising, It was totally opposed to the related statistics in Northwest China show that the reform of initially location is relative optimization, but on the whole reform ago whole Guangdong Province development of backward, industry of Guangdong Province development of backward, and the industry structure also unstable. After the reform, implant the rural contract responsibility system by China was not immediately stimulate the enthusiasm of labor and increase in agricultural production value, Basically shown by the industry fundamentals.

TL of Guangdong province in 1978-1984 change about 1 year. In 1978, Guangdong Province, mainly in agriculture, and with the reform Guangdong province's GDP in increasing, however. Source of the growth are industrial vigorous growth, shown by the industry fundamentals. As show in figure TL and TS common fluctuations in 1985, this moment economic in reform of the stage in 1984, performance but in 1985.

Economic reform system began in this period, adopted in 1984, the decision of the CPC Central Committee on economic reform. Guangdong Province developing commodity economy, (different from the market economy), develop the private economy and other foreign-funded enterprises, separate political and corporate inspire the enterprise vitality Guangdong Province whole economic system reform got a great result in city.

Starting from the early 90's, focused market system construction in Guangdong Province, focusing on the development of secondary industry and tertiary industry to promote the role of the market, the Northwest leading the construction in the period of about 15 years, so during the further rationalization of the industrial structure, TL values tend to be smooth. But the effects of the 1997 Asian financial crises, rationalization of the industrial structure and upgrade have had a varying degree of fluctuation, rationalization of volatility.

In 2000 years TL dropped drastically due to a country developing the West-East electricity transmission and coal transportation from north to south of infrastructure investment, relatively lower tertiary industry, more rational industrial structure. Extension of the market economy after entering WTO, and stimulate the development of enterprises. TL declining also shows that the economic system as a whole is not perfect, irrational rules and regulations hinders the free flow of the factors of the economy. The change of TS enters a period of growth rapidly, 
the main reason is the development of tertiary industry rapidly.

After 2008 the global of economic crisis, in 2009, the economic began appeared, due to China of economic system protection role and market are not developed, in while the global impact hugely, in industry structure aspects, Guangdong of impact does not dramatic, from 2011 began, firstly the GDP growth of china decrease one-digit growth since the reform and opening-up from macro level of China. Guangdong Province appears bankruptcy of enterprise, labor difficult, resources shortage, short-life-cycle of enterprise, regional development unbalance, and Economic and financial reforms in government administration bound predicament and lower global economic vitality, and so on a series of economic challenges.

\subsection{The Impact of Industrial Structure on Economic Growth}

In the analysis of economic growth and fluctuation, through the relevant analysis of Chinese economic historian, will be China's 1978-2009 economy is divided into 4 stages, in this article to illustrate the institutional building policy observation period will be extended to 1970-2014, be divided into 6 stages. By analyzing internal inspection, it can generalized according to judge whether the outcome meets the estimate assumptions.

Table 1. Internal inspection

\begin{tabular}{lll}
\hline Assuming & The f statistic & P-value \\
\hline ILNTL not Granger cause of IY & 0.73515 & 0.6826 \\
IY is not Granger cause of ILNTL & 1.11411 & 0.4234 \\
IY is not Granger cause of ILNTS & 1.02414 & 0.4772 \\
ILNTS not Granger cause of IY & 1.21385 & 0.3699 \\
IX3 not Granger cause of IY & 0.72991 & 0.6866 \\
IY is not IX3 Granger cause & 1.16845 & 0.3934 \\
IX4 is not Granger cause of IY & 0.86506 & 0.5850 \\
IY is not Granger cause of IX4 & 1.15011 & 0.4033 \\
\hline
\end{tabular}

According to the above table, variables interacts each other. The Generalized estimated results indicate that economic growth received the influence of industrial structure, and greater long-term effects of TS. TL and TS 1977-1978 is negative to the economic impact of this phase indicates that the economic system is there is a big problem. 1978-1984 TS contribution to economic growth is large. 1985-1991 TS contributions is further increasing, and TL is promoting, but it plays a small role. TL 1992-2000 and 2000-2008 contributions from low to start to reverse, and further illustrate this period of industrial structure, the trend development to 2014. TS contributions during this period are limited.

Table 2. Impact of industrial structure change on economic growth

\begin{tabular}{|c|c|c|c|c|c|c|c|}
\hline \multirow{2}{*}{$\begin{array}{l}\text { Variable } \\
\text { Time period }\end{array}$} & \multicolumn{7}{|l|}{$\Delta \mathrm{g}$} \\
\hline & $1970-2014$ & 1970-1977 & 1978-1984 & 1985-1991 & $1992-2000$ & $2001-2008$ & 2009-2014 \\
\hline$\Delta \operatorname{lntl}$ & 53.582 & 57.915 & 45.587 & 65.435 & 51.090 & 123.754 & 53.761 \\
\hline$\Delta \operatorname{lnts}$ & 96.049 & 104.432 & 116.42 & -5.2165 & 58.422 & 755.98 & 49.401 \\
\hline$\Delta \mathrm{g}^{*} \Delta \operatorname{lntl}$ & 0.4715 & -0.5592 & 0.4042 & -0.5611 & -0.459 & 1.080 & 0.4884 \\
\hline$\Delta \mathrm{g}^{*} \Delta \ln \mathrm{ts}$ & 0.8320 & 0.8320 & 1.0751 & 0.0254 & -0.497 & 6.680 & 0.4521 \\
\hline$\Delta \mathrm{g}$ & 111.64 & 106.58 & 110 & 114.68 & 114.73 & 113.14 & 109.75 \\
\hline TL-effect & 0.9373 & -1.6864 & 1.114 & 1.0810 & -1.663 & 1.550 & 0.1494 \\
\hline TS-effect & 3.1631 & 15.757 & 1.842 & 2.3014 & 1.2996 & 0.174 & 0.2205 \\
\hline
\end{tabular}




\subsection{The Impact of Industrial Structure on Economic Fluctuations}

According to the outcome, the impact of industrial structure on economic fluctuations is so significance.

Table 3. Impact of industrial structure on economic fluctuations

\begin{tabular}{llll}
\hline Dependent variable & Economic fluctuations & Trend of fluctuation & Cycle of fiuctuation \\
\hline$\Delta \operatorname{lntl}$ & 1.99 & 24820.45 & 25375 \\
$\Delta \operatorname{lnts}$ & -4.71 & -14603.18 & -19593 \\
$\Delta$ vol $^{*} \Delta \operatorname{lntl}$ & -0.47 & -6.39 & -5.8 \\
$\Delta$ vol $^{*} \Delta \operatorname{lntl}$ & 1.09 & 2.84 & 4.57 \\
TL-effect & -1.989979505 & -24820.44972 & -25374.99975 \\
TS-effect & 4.709952469 & 14603.17988 & 19592.9998 \\
\hline
\end{tabular}

As can be seen from the analysis of economic fluctuations were mainly caused by TS, it can be seen from the analysis that the economic fluctuations were mainly caused by TS. From the perspective of the trends and the cycles, TS occupies a larger responsibility among the cause of economic cycle swings. TS on trend volatility shock is less than the cycle impact.

It can be seen from the analysis of the result, the upgrade of industrial structure is responsible for economic fluctuations, while rationalization of industrial structure contributed to offset economic fluctuations. Both of which can contribute to the economic growth, but the contribution of industrial structure upgrading more. The economic analysis also verifies, rationalization of the industrial structure is essentially labour under the optimal configuration of the reasonable measure of economic output. In Guangdong's economic development was actually in economies, China's huge labor force distribution problem. Labour tremendous tie in 1970-1978 communes, 1978-1984 labor began the liberation of the first, 1985-1991, consisting of different labor economies began development of the enterprise, 1992-2000 businesses continue to grow, and 2000-2008 entered a period of rapid growth, 2009-2014 businesses adversely affected by various internal and external problems.

However, the rationalization of industrial structure is not the whole of the industrial structure. The essential of the development of the tertiary industry is the nature of upgrading of industrial structure. Large upgrades occurred in Guangdong Province's in the 90 's, at that time , the services which started from scratch greatly optimized industrial structure, but later also led to the risk of economic fluctuations. The third industry can develop economy in a great degree, but also can bring about larger-scale fluctuations.

3.3 The Policy Analysis

Table 4. Competitiveness of Guangdong 2012 sensitivity coefficient and industrial distribution coefficients were greater than 1

\begin{tabular}{lcl}
\hline Industry sector & $\mathrm{Si}$ & $\mathrm{Tj}$ \\
\hline Chemical Industry & 3.2927 & 1.1841 \\
$\begin{array}{l}\text { Communication Equipment, Computer and other } \\
\text { Equipment Manufacturing }\end{array}$ & 3.0636 & 1.5787 \\
Metal Smelting and Calendering processing industry & 2.31 & 1.3585 \\
Fabricated Metal Products & 1.5745 & 1.3098 \\
Fuel Gas Production and Supply Industry & 1.3928 & 1.468 \\
Electrical Machinery and Equipment Manufacturing Industry & 1.3582 & 1.4216 \\
Paper Printing and Cultural Educational and Sport Goods & 1.3467 & 1.2128 \\
Transportation and Warehousing Industry & 1.1863 & 1.3754 \\
Textile Industry & 1.0326 & 1.1067 \\
\hline
\end{tabular}


To further analyze what kind of policies should be taken through the analysis of the leading industries, and provide the basis for policy recommendations. Leading industries in the tertiary industry of communications equipment, computers and other electronic equipment manufacturing and transportation and warehousing sectors, can be seen from the overall analysis, the leading industry of Guangdong Province dominated by secondary industry, tertiary industry is less.

\section{The Policy Recommendations}

According to the analysis, government should develop Chemical Industry and Metal Smelting and Calendering Processing Industry, Fabricated Metal Products Industry, Fuel Gas Production and Supply Industry, Electrical Machinery and Equipment Manufacturing Industry, Paper printings, Cultural Educational and Sports Goods and Textile Industry.

Textile Industry is encouraged the development of technical courses, not in favor of traditional backwardness of enterprise development. However, developing transportation and warehousing, for communication equipment, computers and other electronic equipment manufacturing industry should be encouraged to develop, but sound system-building in fixed investment in high-tech enterprises. Guangdong is firstly to develop advancing manufacturing of high-tech industries and modern services. The key to improve technology intensive industry is to fully enhance the capability of independent innovation, to master the core technology.

The development of innovation industry can occupy the industry value chain, and it will form a good system. The government should encourage financial institutions to innovate financial products and services. It is significant to establish green financing channel. Financial institutions actively provide services for energy saving and environmental protection industry, which are fixed investment loans, project finance loans, financing lease and bill discount. Relying on the platform of the existing ecological industrial demonstration park and circular economy industrial park, we should establish a batch of energy conservation and environmental protection industry base. We should promote the Pearl River Delta to form industrial concentration zone, which is energy conservation and environmental protection technology research as the core. The government should perfect the system of the third industry construction, especially the financial industry.

\section{References}

Gan, C. (2011). Chinese industrial structure changing influenced economic growth and fluctuations. Study on Economics, 8(5).

Gao, H. (2002). Regional Economics. Beijing: China Renmin University Press, pp.184-185. (in Chinese)

Jian, X., Shen, Z., \& Liu, N. (2007). The Discussion and Analysis of the Evolution of Difference between North, Central and South Jiangsu Province in Economic Development and Its Reason. Inquiry into Economic Problems, (2), 53-59. (in Chinese)

Lin, X. (2012, May). The Private Enterprise Research in Guangdong. Northwest Sci-Tech University Master's degree thesis.

Luo, Y., \& Wei, H. (2005). A Study on Regional Difference of Industrial Structure and its contribution to Economic Growth in HUNAN-Analysis Based on Shift-Share Way. Economic Geography, (7), 491-494. (in Chinese)

Qiu, M. (2012, May). On Financial Supporting of Adjusting Industry Structure in Guangdong. Jinan University Master's degree thesis.

Syrquin, M. (1998). Modern Economic (endogenous) Growth and Development. In Coricellif(Ed.), New Theories in Growth and development (pp. 78-101). St.Martin's Press.

Zhou, Y. (2011, June). Econometric analysis of the differences financial development for regional and upgrading industrial structure. Jinan University Master's degree thesis. 